\title{
IDEOLOGIA ANTIGÊNERO E A CRÍTICA DA ERA SECULAR DE SABA MAHMOOD ${ }^{1}$
}

\author{
Judith Butler ${ }^{2}$
}

\begin{abstract}
Resumo: Neste artigo, Butler retoma o argumento de Mahmood sobre secularismo, direito de família e desigualdade de gênero no Egito para compreender a "ideologia de antigênero" nos Estados Unidos e alhures. Ao invés de vê-la como ressurgência de um fenômeno pré-moderno, Butler sugere que pode ser melhor entendida como uma reação à recente incursão de movimentos sociais na última jurisdição da religião no contexto do Estado secular: a esfera privada da família.
\end{abstract}

Palavras-chave: Ideologia de Gênero; Secularismo; Direito de Família.

ANTI-GENDER IDEOLOGY AND MAHMOOD'S CRITIQUE

OF THE SECULAR AGE

\begin{abstract}
In this paper, Butler engages with Mahmood's argument about secularism, family law and gender inequality in Egypt, in order to make sense of "anti-gender ideology" in the U.S. and elsewhere. Instead of seeing the latter as the resurgence of a pre-modern phenomenon, Butler suggests that it might be best understood as a reaction to the recent incursion of social movements into religion's last jurisdiction in the secular state: the private sphere of family law.
\end{abstract}

Keywords: Gender Ideology; Secularism; Family Law.

1 Traduzido por Letícia Cesarino, a partir de "Anti-Gender Ideology and Mahmood's Critique of the Secular Age". No original, a expressão "anti-gender ideology" aparece com o prefixo "anti" associado ora ao termo "gênero", ora a "ideologia". Mantivemos a ambivalência na tradução, de acordo com o contexto.

2 Judith Butler é filósofa e teórica do gênero. Seu trabalho tem influenciado a filosofia política, a ética e a terceira onda do feminismo e da teoria literária. Desde 1993, ela ensina na Universidade da Califórnia, Berkeley, onde é professora no Departamento de Literatura Comparada e no Departamento de Teoria Crítica. E-mail: jpbutler@berkeley.edu.

Debates do NER, Porto Alegre, Ano i9, N. 36, P. 2 I9-235, Ago./Dez. 20 i 9 
Em Religious Difference in a Secular Age: a Minority Report, Saba Mahmood dedica um capítulo ao tema "Secularismo, direito de família e desigualdade de gênero". Sua discussão ataca a suposição comum de que o direito de família seria governado por autoridade ou códigos religiosos - algo pré-moderno, que persiste na modernidade enquanto uma sobrevivência. Ela argumenta que essa visão, historicamente desinformada, desconsidera que, quando o direito de família é relegado ao domínio privado da religião, a própria religiáo é transformada em uma questáo privada, e casamento e divórcio tornam-se objetos nấo apenas da religiáo, mas da lei religiosa em particular. Ainda que uma religião tradicionalmente lidasse com questôes relativas a casamento e família através de meios năo-legais (costumes, normas, consulta a autoridades religiosas), em condiçóes seculares ela se torna um sistema ou autoridade legal concorrente. A perspectiva que vê no direito de família de base religiosa uma sobrevivência pré-moderna é portanto incapaz de explicar o modo como o estado secular estabeleceu o direito de família como traço definidor da própria religiáo - o que corrobora o modo como o secularismo redefine a religiáo e suas preocupaçóes essenciais. Convençóes e normas envolvendo a vida familiar só são entendidas como "legais" quando o direito secular se diferencia da lei religiosa, e, no mesmo movimento, define a jurisdiçấo adequada desta última.

Mahmood considera casos de conversão e divórcio no direito de família cristão copta no Egito moderno - ou melhor, as tensas negociaçốes e conflitos abertos entre autoridades da Igreja e do Estado, onde estas últimas pretendem defender uma hegemonia presumidamente muçulmana. Seu argumento avança por várias etapas, e conclui sugerindo que "secularismo é uma modalidade compartilhada de estruturação político-legal que atravessa o divisor Ocidente e não-Ocidente" (Mahmood, 2016, p. 147). Com efeito, no mesmo capítulo, Mahmood havia feito referência ao trabalho de Janet Halley e Kerry Rittich (Halley; Rittich, 2010), que argumentam que o direito de família só emerge como esfera legal autônoma no século dezoito. Contra uma forma de liberalismo político que prioriza o individualismo e a racionalidade autointeressada no campo dos mercados e contratos, a 
"família" vai se tornando a esfera na qual são prescritos e regulados laços de afeto, condiçóes de coabitação e casamento, e regras relativas a trocas sexuais. É portanto como consequência do direito de família que a família passa a ser aceita como lócus do cuidado, da reprodução e da moralidade sexual (Mahmood, 2016, p. 120). Em outras palavras, o investimento afetivo na família é resultado do direito de família, isto é, da "modalidade secular de estruturação político-legal” (Mahmood, 2016, p. 147) produzida no curso do desenvolvimento do direito de família.

Embora esse processo venha acontecendo no Egito moderno e em muitos outros países e regióes sujeitos a poderes seculares, ele não vem acompanhado de uma compreensão da sua operação global; pelo contrário, tem alimentado formas de nacionalismo. No argumento de Mahmood, "supôe-se que o direito de família ... emana de, e expressa, 'o espírito do povo"” (Mahmood, 2016, p. 120). Seguindo Halley e Rittich (2010), ela aponta que o direito de família é visto como representando e preservando aquilo que é tradicional, autêntico, mas também um espírito nacional - quando não um nacionalismo explícito. Contra a visão de que o direito de família preserva esses valores nativistas, Mahmood argumenta que esses valores são retroativamente delegados à família através do direito de família. $\mathrm{O}$ caráter "arcaico" ou "primordial" desses valores é, na realidade, produzido pelo secularismo moderno, embora pareçam preceder a modernidade. A própria anterioridade temporal é estabelecida por poderes seculares - um ponto corroborado pelo fato de que, antes do século dezoito, o próprio direito de família era inexistente. Mesmo a proibição copta do divórcio é um fenômeno moderno, vista a longa história de permissibilidade do divórcio dentro da tradiçáo copta - ou seja, antes da obrigação de que problemas maritais passassem a ser resolvidos por meio de um aparato legal específico, que teve que ser produzido para tal.

No que segue, proponho reconstruir o argumento de Mahmood de modo a lançar luz no movimento contemporâneo de oposição à "ideologia de gênero". A ideia da ideologia de gênero emergiu nos anos noventa, quando o Pontifício Conselho para a Família alertou contra a noção de 
"gênero" enquanto ameaça à família e à autoridade bíblica. A ideia de gênero como construção social desencadeou a crença de que indivíduos podiam escolher seu próprio gênero, ou viver sem os constrangimentos do casamento e da heterossexualidade. Na Argentina, Joseph Scala publicou um livro atacando a "ideologia de gênero" que foi amplamente distribuído por igrejas evangélicas. Ele alertou para o caráter agressivo e destrutivo do conceito, sugerindo que "gênero" seria contrário tanto à religião quanto à ciência. Nos anos que se seguiram, gênero se tornou uma questão saliente em eleiçóes no Brasil, Costa Rica, Colômbia, França, Suíça, Alemanha e, mais recentemente, intensamente disputada na Hungria (onde os estudos de gênero foram abolidos) e nos Bálcãs.

Em todos esses contextos, gênero é entendido enquanto uma "ideologia” singular que refuta a realidade da diferença sexual e busca se apropriar do poder divino de criaçáo para aqueles que desejam criar seus próprios gêneros. $\mathrm{Na}$ Alemanha, a ideologia de gênero - ou, de fato, os estudos de gênero são frequentemente caracterizados como totalitários. No Brasil, a ideia da nação, e a própria masculinidade, são vistas como ameaçadas pela "ideologia de gênero". Parece não haver interesse algum pelo que de fato ocorre no complexo e conflituoso campo de estudos de gênero e sexualidade. Ele é unificado como um tipo de fantasma, que serve para justificar o fato de que praticamente ninguém lê os textos produzidos pelo campo, ou mesmo considera seus argumentos. Na Suíça, fui abordada por uma mulher que disse que rezava por mim, e quando eu perguntei por que, ela explicou que gênero era "diabólico", e que ela esperava que eu encontrasse redenção por minha responsabilidade em difundir o termo, ou a teoria, ou o fantasma. Quando lhe perguntei se ela havia lido meu trabalho, ela exclamou que jamais leria livro algum sobre gênero!

O furor começou alguns anos atrás, quando o Pontifício Conselho para a Família, então dirigido por Joseph Ratzinger, alertou que teóricos de gênero estavam colocando a família em risco ao questionar a noção de que papéis sociais apropriadamente cristãos podiam ser derivados do sexo biológico. Era da natureza do sexo feminino realizar trabalho doméstico, e 
do masculino, exercer atividades na vida pública. A integridade da família, entendida como cristã e natural, estava sendo ameaçada pela ideologia de gênero. Os argumentos utilizados eram marcadamente pré-feministas - o que talvez ajude a explicar por que a primeira objeção da Igreja Católica ao conceito de "gênero" foi considerada esdrúxula, ou mesmo risível, para feministas que, naquele momento, não anteciparam as implicações daquela oposição. Ratzinger externou sua preocupação na Conferência de Beijing sobre as Mulheres de 1995, e novamente em 2004, enquanto diretor do Pontifício Conselho para a Família, em uma Carta aos Bispos, onde destacou o potencial do "gênero" para destruir valores femininos importantes para a Igreja, assim como a distinção natural entre os dois sexos (Vatican, 2004). Enquanto Papa Bento XVI ele foi além, alegando, em 2012, que essas "ideologias" negavam a "dualidade pré-ordenada entre homem e mulher", e portanto "a família" enquanto "realidade estabelecida pela criação." Porque homens e mulheres foram criados por Deus, continuou ele, aqueles que buscam criar a si mesmos negam o poder criativo de Deus, e são movidos por crenças ateias. Em 2016, mesmo o Papa Francisco, que ocasionalmente apresenta visóes progressistas, continuou na linha do seu antecessor: "Estamos vivendo um momento de aniquilação do homem como imagem de Deus". Ele incluiu especificamente como uma das vias deste ataque a "[ideologia de] gênero", e se mostrou claramente contrariado ao afirmar que "Hoje crianças - crianças! - são ensinadas na escola que todos podem escolher seu sexo ... Isso [sic] terrível!”. Ele então acenou positivamente para Bento XVI, alegando que "Deus criou homem e mulher; Deus criou o mundo de uma certa forma ... e nós estamos fazendo o oposto". Essa perspectiva faz crer que os humanos teriam se apropriado do poder criativo de Deus. Papa Francisco foi ainda além, ao sugerir que proponentes do gênero seriam os mesmos que apoiam ou utilizam armas nucleares, e que seu alvo seria, em última instância, a própria criação. Isso sugere que, o que quer que seja o gênero, ele carrega enorme poder destrutivo nas mentes de seus opositores - com efeito, uma capacidade destrutiva terrível e inimaginável. É representado como uma força demoníaca de destruição, contraposta aos poderes criativos 
de Deus. Essa é uma das razóes pelas quais o gênero é entendido como um exercício de poderes demoníacos: uma "ideologia diabólica”.

Talvez tenha sido o apoio papal que, em 2015 e 2016, encorajou bispos em todo o mundo a ampliar a campanha contra a ideologia de gênero em um projeto internacional, que atravessasse hemisférios, afetasse eleições na Colômbia, México e Costa Rica, e, mais recentemente, desempenhasse um papel importante na eleição de Jair Bolsonaro no Brasil. Seu discurso de posse em janeiro deste ano incluiu um compromisso pela erradicação da "ideologia de gênero nas escolas", jurando resistir à "submissão ideológica”. Uma vez eleito, tem buscado abolir a educação sexual nas escolas, substituindo-a por um currículo que reforce a ideia da diferença binária de gênero. Em outubro de 2018, a Hungria não apenas retirou estudos de gênero da lista de programas de mestrado credenciados, como forçou a Universidade Centro-Europeia, reconhecida por seu programa internacional em gênero, a mudar-se para Viena.

$\mathrm{Na}$ França, uma batalha legal pelo casamento gay vencida em 2013 sofreu um contragolpe no ano seguinte. Um currículo proeminente na França chamado "ABC da igualdade" oferecia aos estudantes um modo de pensar a diferença entre sexo biológico e gênero cultural, e foi descontinuado após fortes acusaçóes públicas de que a teoria de gênero estava sendo ensinada em escolas primárias. O Papa Francisco se encontrou com um dos organizadores do esforço pela eliminação do programa. Argentina, o país de origem do Papa, é o país com leis mais progressistas no campo da liberdade de gênero, ao permitir que qualquer um mude de gênero sem autorização médica. Em 2014, em reação à Lei da Identidade de Gênero aprovada em 2012, La ideología de género foi publicado por Jorge Scala e começou a circular entre comunidades cristâs, tanto católicas quanto evangélicas, na Argentina e, após traduzida, também no Brasil. Na região espanhola da Andaluzia, o partido ultraconservador Vox solicitou ao partido de centro-direita Ciudadanos que combatesse o que chamavam de "jihadismo de gênero". Eles se opunham ao foco em homens que cometiam violência contra mulheres e pessoas trans, 
convocando uma oposição à violência "intra-familiar" no lugar da violência de gênero, sob a alegação de que homens também podem ser vítimas.

A plataforma da aliança anti-ideologia de gênero entre evangélicos e católicos de direita é clara: eles se opóem ao feminismo, aos direitos LGBTQI, especialmente ao casamento gay e ao direito médico e legal de pessoas trans, mães solteiras, pais e mães gays, entre outros. Minha sugestão é que, na medida em que as políticas econômicas neoliberais devastaram a vida laboral e a perspectiva de futuro de muitas pessoas que hoje enfrentam trabalho contingente e dívidas impagáveis, a virada contra o "gênero" emergiu como um modo de defender um sentido tradicional de posição e privilégio. Também traça uma linha entre público e privado, protegendo a família e seu privilégio patriarcal do mercado, onde a humilhação e a prescindibilidade tornaram-se a norma. $\mathrm{O}$ investimento tanto nacionalista quanto tradicionalista na proibição do casamento gay, de famílias gays e lésbicas e seus direitos a adoção, de direitos de trans e travestis, da adoção por parte de mães e pais solteiros e seu acesso a tecnologias reprodutivas, na desigualdade de gênero, assim como no próprio conceito de "gênero" é efeito de uma defesa, por vezes violenta, da família heteronormativa enquanto última barreira contra a devastação das forças de mercado. $\mathrm{O}$ movimento anti-ideologia de gênero cresceu na esteira da promulgação de leis sobre o casamento gay, alegando que a religião deveria ser o árbitro de arranjos maritais, e que a família heterossexual com seus papéis distintos, naturais e hierárquicos para mulheres e homens estaria sendo minada pela legislação "progressista". Opor-se a, ou reverter, tendências inclusivas no direito de família, ou demandar novas leis proibindo formas de procriação ou adoção fora da família tradicional, assim como mudança do gênero designado ao nascer ou a afirmação de igualdade entre homens e mulheres - tudo trabalha para o mesmo fim. Embora seja normalmente presumido que avanços nos movimentos por direitos LGBTQ dependem da intensificação do secularismo, eu sugiro que o secularismo é ao menos parcialmente responsável pela intensificação da forma-família como foco de conflito legal e moral. Entretanto, para avançar esse argumento, devemos estabelecer (a) como a 
família tem se tornado foco de investimentos nacionalistas e nativistas táo intensos; e (b) como o secularismo tem estruturado o campo deste debate, distribuindo a intensidade de seus investimentos em formas sexuais e de gênero naturais ou normativas.

Talvez pareça um salto grande dos dilemas legais do divórcio copta para o movimento anti-ideologia de gênero. Lembremos, todavia, que os efeitos da secularização da forma-família têm, para Mahmood, um caráter global, atravessando o divisor entre Oriente e Ocidente. Se eles também atravessam o divisor entre Norte e Sul é outra questão, visto que os ideólogos do antigênero no Brasil e na América Latina tendem a alegar que "gênero" é uma importaçáo dos Estados Unidos e do Norte global.

Mahmood argumenta que os grandes conflitos entre muçulmanos e cristáos coptas nas últimas décadas têm, em larga medida, girado em torno de quando e como o divórcio torna-se possível. Diversos casos bem difundidos seguem a mesma linha: uma mulher copta desaparece ou deixa sua família, presume-se que ela tenha se convertido ao Islã, e que tal conversão tenha sido forçada. Quando homens ou mulheres convertem-se ao Islá para poderem se divorciar e casar novamente, sempre são levantadas questôes sobre se eles ou elas o fizeram de forma voluntária. Visto que o divórcio está proibido no Cristianismo copta há mais de trinta anos, o único modo de alguns deixarem uma situação marital indesejada é mudar de religião, e assim recair sob uma jurisdição de família diferente: no caso da adjudicação contemporânea do divórcio, o Islã é mais liberal que a religião copta. A conversão ao Islã tornou-se uma forma de exercer uma opção sexual ou marital que seria de outro modo impossível. É significativo que, se um homem copta converte para o Islâ, ele pode permanecer casado com sua esposa copta, mas uma mulher que converte para casar-se novamente terá ambos seus casamentos - o anterior e o prospectivo - anulados pelas autoridades copta e muçulmana (Mahmood, 2016, p. 113). Ela não pode utilizar a conversão para exercer uma nova opçáo sexual ou marital. Não obstante, essa proibiçáo codifica uma fantasia recorrente de que nenhuma mulher poderia, ou iria, escolher se converter, e que qualquer conversão 
que eventualmente ocorra seria portanto forçada. A mulher é entendida pelos representantes coptas como carente de desejo ou vontade sexual, sem preferências próprias de companheiros ou parceiros maritais, e simplesmente sujeita a manipulação e coerção por uma comunidade muçulmana ardilosa e nefasta. Com efeito, a proliferação de "estórias de abdução cotas", em que mulheres coptas são recrutadas, sofrem lavagem cerebral e são fisicamente coagidas a converter ao Islá, é testemunho da noção de que as mulheres não iriam - não poderiam - exercer sua própria agência sexual ao abandonar uma religião que não lhes permite deixar o casamento ou casar-se novamente.

Contra aqueles que veem conflitos entre coptas e muçulmanos como um antagonismo tribal arcaico, Mahmood deixa claro que foi o Estado secular que produziu tais conflitos. Estados seculares têm buscado relegar a religião à esfera privada. Até certo ponto, questóes envolvendo moralidade, a forma da família e seus conflitos, desenvolvimento de gênero e educação sexual foram designadas para a esfera privada. Como efeito, cada vez que leis favorecendo diversidade de gênero, protegendo orientaçóes sexuais ou expandindo as fronteiras da família, do casamento ou da adoção penetram na esfera pública, aparecem objeçóes religiosas. Essas objeçóes atacam temas específicos, mas também se contrapóem como um todo ao fato de essas questôes estarem sendo definidas fora do domínio religioso. Sob o regime secular, esse domínio é considerado privado, separado da esfera pública e de suas leis universalistas, e controlado pela religiáo. Para Mahmood, os conflitos entre religióes frequentemente se dão em torno de questóes como gênero, sexualidade, formas de família, adoção e divórcio precisamente porque o Estado secular relegou ou designou tais questóes para a religiáo e moralidade privada. Estas nem sempre foram a marca das religióes, mas acabaram tornando-se como resultado dos poderes delimitadores do Estado secular. No Egito, por exemplo, onde o direito de família opera em paralelo à lei civil comum, o Islã é visto exclusivamente como jurisdição do direito de família religioso. A ideia de um direito de família religioso reestrutura o significado e o funcionamento da religião muçulmana, e é, na visão de Mahmood (2016, p. 115), uma "invenção moderna”. Em suas palavras, 
o secularismo moderno associou perniciosamente questóes religiosas, sexuais e domésticas quando a família se tornou o lugar central para a reprodução da moralidade e da identidade religiosas, exacerbando padróes preexistentes de hierarquia religiosa e de gênero (Mahmood, 2016, p. 115).

Não apenas a religião ficou encarregada de regular a moralidade sexual, conflitos de família e significados de diferença sexual, como foi privada de qualquer participação no domínio público, incluindo na vida civil e na esfera da ética pública como um todo. Não havia lei separada na Shari’a antes do Estado secular estabelecer uma jurisdição religiosa sobre assuntos de família. Da mesma forma, não havia proibição copta do divórcio antes da emergência do direito de família copta, precisamente porque não havia direito de família até que os direitos público e privado fossem separados, e a religião, relegada a este último. A própria distinção entre privado e público emerge a partir dos poderes da autoridade secular de fazer e reforçar essa distinção.

Do ponto de vista da autoridade propriamente religiosa, não há referência a essa genealogia dos poderes do Estado secular de designar e restringir sua ação à esfera privada, definida primariamente pela família e seu mandato moral de reproduzir sua própria estrutura enquanto uma forma social natural e normativa. Essa designação foi, em larga medida, aceita, assim como a tarefa de regular a vida sexual, os laços de intimidade, as condiçóes de casamento e divórcio em um domínio próprio. A forma da família não é, em si, contingente, e nem as regras que governam casamento e divórcio, e que decidem quem tem o direito de se casar, se divorciar e se reproduzir.

Náo estou táo certa quanto Mahmood de que secularismo seja o nome para uma modalidade de poder que produz todos esses fenômenos. Minha impressão é que diversos poderes convergem neste ponto. Noto, por exemplo, que a distinção entre os domínios público e privado é uma característica central das sociedades capitalistas, assume uma forma específica sob o neoliberalismo, e que modos antigos e novos de produzir desigualdade de gênero têm vidas históricas desde a época clássica até o presente que ultrapassam ou 
embaraçam a distinção entre o secular e o religioso. Não obstante, Mahmood é persuasiva ao argumentar que o secularismo assegura um domínio privado para a religião, e, ao fazê-lo, orquestra uma convergência significativa entre autoridade religiosa e política familiar, sexual e hierarquias de gênero. Ceder controle sobre questôes envolvendo família, casamento e sexualidade é, para muitas autoridades religiosas na era secular, perder o único tipo de autoridade que ainda detêm. É possível vê-lo no movimento contra a chamada "ideologia de gênero". As acusaçôes feitas em nome de evangélicos e católicos de direita contra o conceito de gênero presumem que "sexo" seja uma categoria adequada para descrever as distinçôes naturais, dadas por Deus, entre homens e mulheres, que a hierarquia entre elas também deriva da natureza e da autoridade bíblica, que qualquer orientação sexual que não se conforme com o mandato da heterossexualidade dentro do casamento é uma afronta às leis naturais, e que qualquer um que assuma um gênero legal que desvie daquele designado ao nascer comete uma monstruosidade. É tentador alegar que o problema é precisamente a religião. Afinal, esses polemistas se fundamentam em textos religiosos, e se opóem a potenciais emancipatórios liberados pelo processo de secularização. Mas por outro lado, categorias como "sexo" raramente aparecem na Bíblia, e é possível selecionar passagens com um número razoável de referências ambíguas a afeição queer que trariam problemas para seus defensores contemporâneos. ${ }^{3}$ De fato, muitos dos argumentos utilizados por aqueles que se opóem ao gênero são enfaticamente modernos, orquestrados dentro de debates seculares, e movidos pela revolta reacionária contra o deslocamento da autoridade religiosa sobre o que eu chamaria de questóes de gênero e sexualidade na sociedade civil - tanto suas leis quanto as formas de reconhecimento que se tornaram mais comuns nos últimos anos.

A parte do argumento de Mahmood que pode ser transposta do modo mais produtivo para o atual cenário de ataques ao "gênero" por cristãos de direita tem a ver com a inversão da sequência temporal. É possível dizer, por

${ }^{3}$ Ver, por exemplo, Case $(2011,2016)$, Dunning (2019) e Penner (2010). 
exemplo, que a proibição do divórcio é a essência da religião copta, ou que a família está no coração do Islã - mas ambas as alegações só tornaram-se possíveis em períodos históricos que são distintivamente modernos e seculares. Em outras palavras, essas "essências" foram estabelecidas; elas não estavam já dadas, na história de cada uma dessas tradiçôes religiosas. Elas não estão na origem dessas religióes, e, não obstante, do ponto de vista presente, são tratadas como se sempre estivessem. Nesse sentido, são instaladas retrospectivamente enquanto origens fictícias. Da mesma forma, a ideia de que o sexo determina o papel da pessoa na sociedade, na família e em arranjos sexuais dificilmente pode ser encontrada na tradição cristã. Toda a ideia do propósito "teleológico" do sexo manifestado em arranjos familiares e sociais específicos só se tornou possível uma vez concluída a sua redução ao "sexo biológico". Afirmar que "no começo, havia o sexo" apaga toda genealogia dessa categoria na sexologia, assim como suas contestaçóes na biologia, sociologia, neurociências, genética, e no Comitê Olímpico Internacional. Com efeito, o sexo natural foi retrospectivamente instalado enquanto um dado biológico, e a redução da vida corporificada aos "sexos" foi produzida através de processos históricos específicos dentro da modernidade. Uma origem torna-se um efeito plausível de um discurso que busca apagar a gênese daquele discurso para afirmar sua autoridade inconteste. A linguagem das orientações sexuais "não-naturais" é semelhante: não há histórico da noção de "orientação sexual" antes do século dezenove, e tampouco da formação de um sujeito entendido como tendo uma orientação desse tipo. $\mathrm{O}$ mesmo poderia ser dito da "família", como já foi demonstrado por muitos historiadores e antropólogos.

Mas talvez a crítica mais relevante venha sendo feita pela literatura feminista sobre neoliberalismo, em autoras como Melinda Cooper e Bethaney Moreton. De formas diferentes, ambas argumentam que a retirada do apoio estatal às famílias, às crianças dependentes e a serviços sociais deslocou a função de apoio básico para as famílias. Esta seria uma razão para a reabilitação ferrenha da família tradicional no exato momento em que sua estabilidade financeira tem sido gravemente comprometida. A autoridade 
das igrejas evangélicas tem se insinuado não apenas para botar ordem moral na família - sem a qual a economia não poderia funcionar - mas para apoiar e aliviar a economia de livre mercado. Não posso ir mais a fundo aqui na complexa aliança entre a proliferação dos evangélicos e o suporte à economia do laissez faire em sua forma neoliberal, mas Moreton (2009) argumentou que mulheres brancas cristãs - a força motriz do movimento evangélico nos Estados Unidos - entendem com clareza que "valores familiares são um elemento indispensável à economia global de serviços, e não um obstáculo" (5). Com efeito, as igrejas evangélicas são parte da livre iniciativa - ou, como diriam alguns, da iniciativa cristã -, e essa convergência é frequentemente colocada como única alternativa ao socialismo ou comunismo, ou às elites acadêmicas. Daí a centralidade do Walmart como "multinacional populista". Assim como valores familiares são indispensáveis à sustentação da economia de serviços, já que apenas o trabalho livre da família pode tornar minimamente suportável seus termos econômicos, redes de bem-estar baseados na fé são indispensáveis para a retração do Estado do seu papel de prestador de serviços sociais aos necessitados. Na medida em que o Estado se afasta de ideais básicos de democracia social, o domínio privado da família e da religião assume um papel cada vez mais central no funcionamento econômico e político da sociedade.

A precariedade crescente dos trabalhadores sob o neoliberalismo, e a depreciação da renda doméstica que a acompanha, impóem à família a tarefa de encontrar suas próprias soluçóes. E a resposta à precariedade parece assumir a forma de uma renovação da autoridade patriarcal, tanto na família quanto na igreja. A ameaça passa então a ser identificada não com os processos de precarização neoliberais, mas com os movimentos culturais e sociais que buscam descentrar ou dissolver essa autoridade. Seria fácil sugerir que a oposição ao "gênero" é um deslocamento sintomático de uma ansiedade produzida pelo neoliberalismo. Pode ser que formas de patriarcalismo que buscam defender o poder patriarcal no interior da família e do Estado (assim como no mundo do trabalho) sejam uma resposta à "emasculação" do trabalhador. Mas há outra dimensão que é mais preocupante: um 
exercício da liberdade que não é constrangido pela liberdade de mercado e sua dependência ideológica na noção de liberdade pessoal. Além disso, em formas neoliberais tradicionais, a liberdade de mercado não se estendia a questóes de moralidade pessoal, embora avançasse múltiplas suposiçóes sobre a importância da disciplina do trabalhador e da gestáo do dia de trabalho. O propósito secular de relegar a família ao domínio da religião parece ter preenchido uma lacuna aberta pela auto-circunscrição neoliberal. A emergência de uma "liberdade" aparentemente secular dentro da esfera privada, tipificada pelo "gênero", opera então conjuntamente com a forma de neoliberalismo que restringe a liberdade (assim como a democracia) à liberdade de mercado. Seria esperado que as autoridades cristãs se opusessem à saturação da racionalidade neoliberal na vida privada (Brown, 2015, p. 30-31), e identificassem movimentos por maior liberdade de expressão de gênero como manifestaçóes de uma "liberdade pessoal" pressuposta tanto pelo liberalismo quanto pelo neoliberalismo; porém, algo diferente parece estar acontecendo. Movimentos sociais são mais que uma coleção de indivíduos, e o conceito de liberdade social avançado por esses movimentos aparece como uma intervenção colonizadora por parte do secularismo e do ateísmo. Curiosamente, a autoridade sobre a família alocada pelo secularismo à religiáo promove hoje uma oposição ao secularismo em nome daquela mesma autoridade. A liberdade à qual as autoridades cristãs se opóem é a da "construção social" e da "liberdade para criar" - uma prerrogativa que, aparentemente, pertence exclusivamente à divindade, e não a coletivos sociais que buscam transformar pressupostos sobre gênero, sexualidade e família.

A ideologia de antigênero difunde fantasias públicas, no Brasil e em outros lugares, de que professores de educação sexual, guiados pelo "gênero", estariam ensinando estudantes a se masturbar, ou a como se tornarem "homossexuais". Partindo da perspectiva de Mahmood, podemos nos perguntar se essas acusações infundadas, como as estórias de sedução coptas, não seriam fantasmas políticos reveladores de um profundo receio de perder a jurisdição sobre tais questôes. Num contexto em que a autoridade patriarcal na família e na igreja emerge como "resposta" aos efeitos precários da financeirização 
global, o argumento de Mahmood assume uma especificidade histórica aguda. Os exemplos citados pretendem alertar a comunidade cristã para as incursôes da cultura pública no domínio da família, isto é, no domínio próprio da Igreja. Se essa Igreja é evangélica ou católica importa menos que o fato de a Igreja ter aceitado sua circunscriçáo, pelos poderes liberais, à esfera privada, e, junto com ela, sua autoridade moral e jurisprudencial sobre questóes de família, casamento, sexualidade e gênero (Scott, 2017, p. 3-15, 30-59, 156-184). A oposição aos direitos legais e movimentos sociais feministas e LGBTQI, à adoção fora do casamento ou ao acesso a tecnologias reprodutivas independente do status marital, baseia-se numa forte aversão aos novos movimentos sociais e culturais que têm buscado reconhecimento, mas também à incursão desses movimentos em seus domínios. Tanto o trabalho não-pago da mulher no núcleo doméstico quanto a garantia da reproduçáo de filhos sáo questionados por movimentos sociais que demandam igualdade para o trabalho da mulher, e que não presumem o tipo de arranjo sexual de que os filhos farão parte.

Entretanto, a autoridade sobre o domínio da família foi circunscrita precisamente pelos poderes seculares que buscaram, inicialmente, restringir as reivindicaçóes universais de igualdade e liberdade a sujeitos de direitos homens, brancos e proprietários. Ao mesmo tempo, permitiram que desigualdades e constrangimentos persistissem como prerrogativa da esfera privada - uma esfera de prerrogativas heteronormativas, patriarcais e racistas. A mesma divisão secular que delimitou a esfera de direitos possíveis enquanto esfera pública permitiu a preservação e reprodução de desigualdades radicais na esfera privada - desigualdades estas que a religião agora perpetua em nome de uma lei natural. Deste modo, a defesa da família enquanto província da religião busca afastar ou abafar críticas de injustiça econômica e restrição de liberdades sociais produzidas por perspectivas feministas e LGBTQI. O fato de o secularismo ter buscado construir suas noçôes de direitos públicos alocando a família na esfera da religião não apenas manteve as mulheres em condiçôes de desigualdade ou destituição econômica, constrangidas dentro de casamentos heteronormativos, como também estabeleceu a religião como 
autoridade punitiva em detrimento de muitas outras possibilidades culturais e sociais - incluindo aquelas compatíveis com um socialismo democrático em que lutas LGBTQI não pareçam "secundárias”. A oposição à “ideologia” de gênero teme especialmente as expressóes de liberdade e igualdade social que comprometeriam o patriarcalismo e o controle que garante à religiáo seu último bastiáo de poder em regimes seculares. A resposta adequada seria aliar a crítica do secularismo a uma visão radical de liberdade e igualdade social, e nós então veríamos a religião assumir relações diferentes com o "gênero" e com os movimentos sociais para os quais ela oferece um atalho no discurso contemporâneo.

\section{REFERÊNCIAS}

BROWN, Wendy. Undoing the Demos, Neoliberalism's Stealth Revolution. Cambridge, MA: Zone Books, 2015.

CASE, Mary Anne. After Gender the Destruction of Man? The Vatican's Nightmare Vision of the "Gender Agenda" for the Law. Pace Law Review, New York, v. 31, n. 3, p. 802-817, 2011.

CASE, Mary Anne. The Role of the Popes in the Invention of Complementarity and the Vatican's Anathematization of Gender. Chicago: University of Chicago, 2016. (Public Law \& Legal Theory Working Papers, 565).

DUNNING, Benjamin (org.). The Oxford Handbook on New Testament, Gender, and Sexuality. Oxford: Oxford University Press, 2019.

HALLEY, Janet; RITTICH, Kerry. Critical Directions in Comparative Family Law: Genealogies and Contemporary Studies of Family Law Exceptionalism. The American Journal of Comparative Law, United States, v. 58, n. 4, p. 753-775, 2010.

MAHMOOD, Saba. Religious Difference in a Secular Age: a Minority Report. Princeton: Princeton University Press, 2016. 
MORETON, Bethany. To Serve God and Wal-Mart: the Making of Christian Free Enterprise. Cambridge, MA: Harvard University Press, 2009.

PENNER, Todd. Women, Gender, and Sexuality in the New Testament and Early Christianity. Oxford Bibliographies: Biblical Studies. 2010. Disponível em: https://www.oxfordbibliographies.com/view/document/ obo-9780195393361/obo-9780195393361-0131.xml\#. Acesso em: 24 jun. 2019.

SCOTT, Joan. Sex and Secularism. Princeton: Princeton University Press, 2017.

VATICAN. Letter to the Bishops of the Catholic Church on the Collaboration of Men and Women in the Church and in the World [by Joseph Cardinal Ratzinger]. Rome, 2004. Disponível em: http://www.vatican.va/roman_curia/ congregations/cfaith/documents/rc_con_cfaith_doc_20040731_collaboration_en.html. Acesso em: 24 jun. 2019.

Recebido em: 28/10/2019

Aprovado em: 28/10/2019 
